\title{
Effect of carburizing treatment on the "fish eye" crack growth for a low alloyed chromium steel in very high cycle fatigue
}

\author{
Zhi Yong Huang a,b,*, Danièle Wagner ${ }^{\mathrm{b}}$, Qing Yuan Wang ${ }^{\mathrm{a}}$, Claude Bathias ${ }^{\mathrm{b}}$ \\ a Sichuan University, No. 29 Jiuyanqiao Wangjiang Road, Chengdu, 610064, China \\ ${ }^{\mathrm{b}}$ Université Paris Ouest Nanterre La Défense, 50 Rue de Sèvres 92410 Ville d'Avray, France
}

\begin{abstract}
A B S T R A C T
A low alloyed chromium steel with a carburizing treatment is studied in VHCF regime with the help of an ultrasonic fatigue machine working at $20 \mathrm{kHz}$ frequency. An infrared camera is applied to study the thermal dissipation during the crack growth period. The number of cycles at the second crack growth stage could be determined by the temperature evolution. The crack propagation model is coupled with thermal dissipation, which permits to estimate the temperature evolution in crack propagation period on specimen surface with the help of the numerical method FEM. The comparison between the results of test and simulation shows that the model is in agreement with the test in the second period of crack propagation.
\end{abstract}

Keywords:

VHCF

SEM

Crack path

Fatigue dissipation

\section{Introduction}

In practice, service life of mechanical components often exceeds $10^{7}$ cycles which is in the so called Very High Cycle Fatigue (VHCF) regime. The ultrasonic fatigue test machine has been applied to investigate the fatigue behavior with a high frequency of $20 \mathrm{kHz}$ [1]. The frequency effect on high strength steel has been studied by Israel Marines [2] in $20 \mathrm{~Hz}, 20 \mathrm{kHz}$, $30 \mathrm{kHz}$ and concluded that there is no prominent influence of frequency on VHCF for high strength steel. The VHCF crack initiation mechanism was explained by Murakami [3]. The "fish eye" crack growth has been studied by Paris and Bathias $[4,5]$ who gave a fracture mechanics approach to estimate the number of cycles of crack propagation.

The high speed of crack propagation releases plenty of heat after the crack initiation in ultrasonic fatigue test. Obtaining the crack propagation cycles [6,7] becomes possible through observation of the temperature evolution on the surface of the specimen because the increase of temperature is significant in the period of crack propagation. An infrared camera is often used to observe the temperature evolution and distribution on the surface of the specimen during the tests. The experimental result is well predicted by the theoretical model given by Paris and Bathias [5]. In the previous papers [5-7], it is assumed that the thermal dissipation is related to the plastic deformation occurring at the

\footnotetext{
* Corresponding author. Tel./fax.:0086 2885406919.
}

E-mail address: huangzy@scu.edu.cn (Z. Yong Huang). tip of the crack. Starting from the hypothesis, Ranc et al. [6] gave the first approximate relation between the plastic strain energy and the thermal energy in order to predict the number of cycles of the crack growth. But, the "ODA" forming stage in crack propagation occupies a large number of cycles in VHCF test [8]. Which part of crack propagation leading to the significant thermal dissipation is necessary to be clarified from the fracture surface analysis.

This paper aims to improve the model which is applied to a low alloyed chromium steel for automobile industry in order to predict the "fish eye" growth. From a practical point of view, the effect of a surface carburization layer has been considered in the improved model. One of the objectives is to know if such surface treatment is capable to significantly change the number of cycles denoted to the "fish eye" crack growth.

\section{Material}

The investigated material is a high-strength steel SAE 5120. The chemical composition is shown in Table 1 . The observations of the polished section by a scanning electron microscope with X-Ray analysis have displayed prominently two kinds of inclusions: manganese sulfides (MnS) and mixed inclusions ( $\mathrm{Al}, \mathrm{Si}, \mathrm{Ca}$, $\mathrm{Mg}, \mathrm{Mn}, \mathrm{S}$ ) whose diameters are lower than $20 \mu \mathrm{m}$ and mostly between 5 and $10 \mu \mathrm{m}$ (Fig. 1) [9].

In order to improve the wear performance of the material, carburization process followed by final grinding (circular) has been applied to the surface treatment of the specimens. In this 


\begin{tabular}{|c|c|c|c|}
\hline \multicolumn{2}{|c|}{ Nomenclature } & \multirow{2}{*}{$\begin{array}{l}N_{p I} \\
N_{p I I} \\
N\end{array}$} & \multirow{2}{*}{$\begin{array}{l}\text { number of cycles for crack propagation stage I } \\
\text { number of cycles for crack propagation stage II } \\
\text { number of cycles }\end{array}$} \\
\hline$a$ & crack length & & \\
\hline$a_{0}$ & crack length at the threshold corner & $\Delta K$ & stress intensity factor range \\
\hline$a_{\text {int }}$ & size of inclusion & $P$ & dissipation power at crack tip per cycle \\
\hline b & Burgers vector modulus & $T$ & temperature \\
\hline E & Young's modulus & $\Delta T$ & temperature increase \\
\hline$e$ & eccentricity of center of crack & $\Delta \sigma$ & stress range \\
\hline$f_{p}$ & crack path factor & $\sigma_{y}$ & yield stress \\
\hline$L$ & thickness of carburization layer & $\sigma_{y}^{\prime}$ & cyclic yield stress \\
\hline$N_{f}$ & number of cycles at failure & & \\
\hline$N_{i}$ & $\begin{array}{l}\text { number of cycles at crack initiation detected by } \\
\text { temperature recording }\end{array}$ & & \\
\hline
\end{tabular}

study, Series $M$ has been treated by low pressure carburization (LPC) followed by quenching to form martensite with retained austenite microstructure (Fig. 2a), and then, followed by surface grinding (circular). Series $\mathrm{P}$ has only undergone surface polish without the heat treatment. Its microstructure consists of ferrite and perlite (Fig. 2b). The LPC (Series M) surface treatment technology applied to the sample allows achieving 700HV hardness. The hardness of the specimens of series P is about $250 \mathrm{HV}$ (Fig. 3).

Table 1

SAE 5120 chemical composition.

\begin{tabular}{lllllllllllll}
\hline & $\mathrm{C}$ & $\mathrm{Mn}$ & $\mathrm{P}$ & $\mathrm{S}$ & $\mathrm{Si}$ & $\mathrm{Ni}$ & $\mathrm{Cr}$ & $\mathrm{Mo}$ & $\mathrm{Cu}$ & $\mathrm{Al}$ & $\mathrm{N}$ & $\mathrm{O}$ \\
\hline $\mathrm{wt} \%$ & 0.22 & 0.83 & 0.012 & 0.03 & 0.22 & 0.15 & 0.8 & 0.04 & 0.15 & 0.031 & 0.008 & 0.003 \\
\hline
\end{tabular}

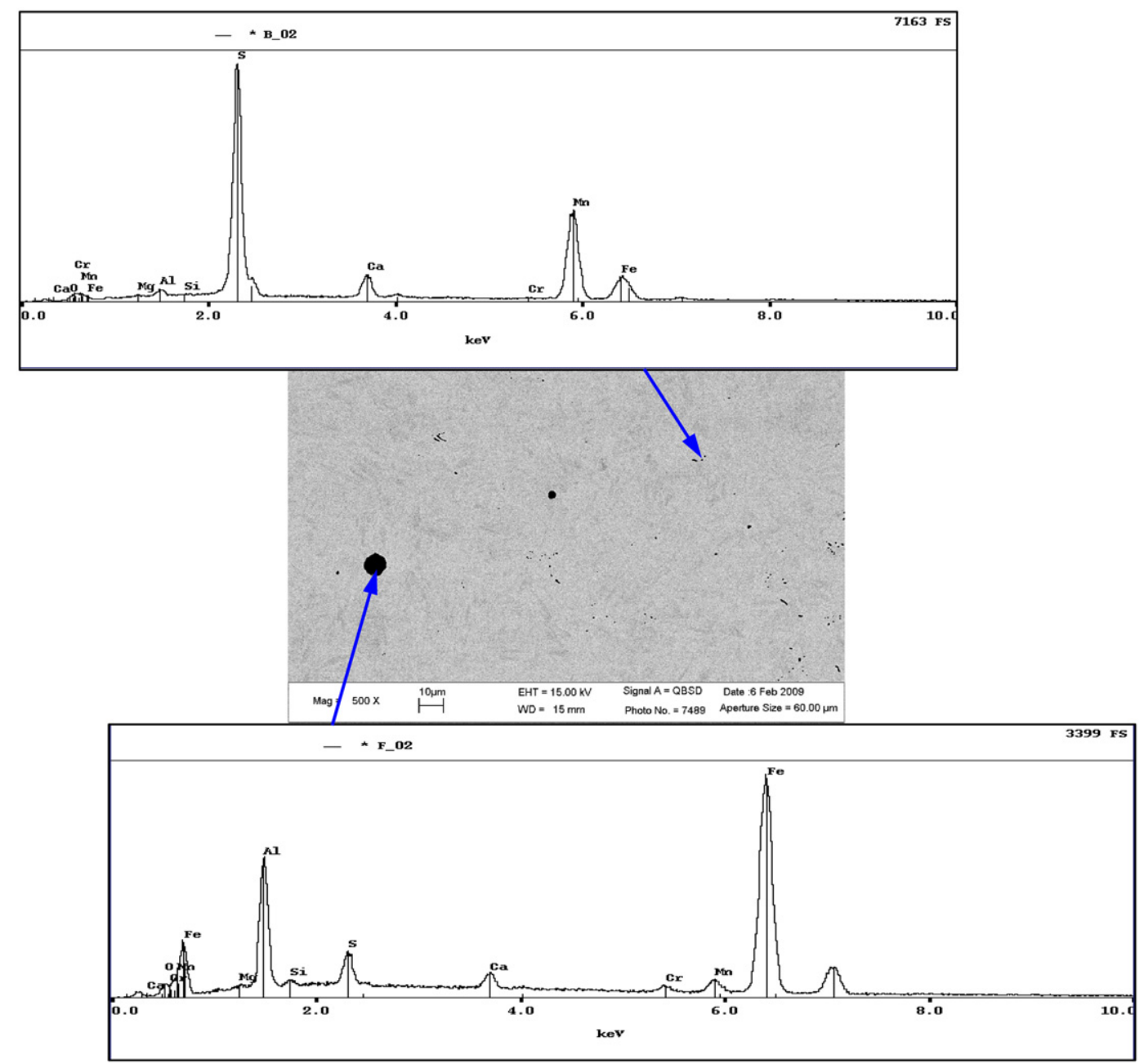

Fig. 1. Inclusions in the material of Series M. 
a

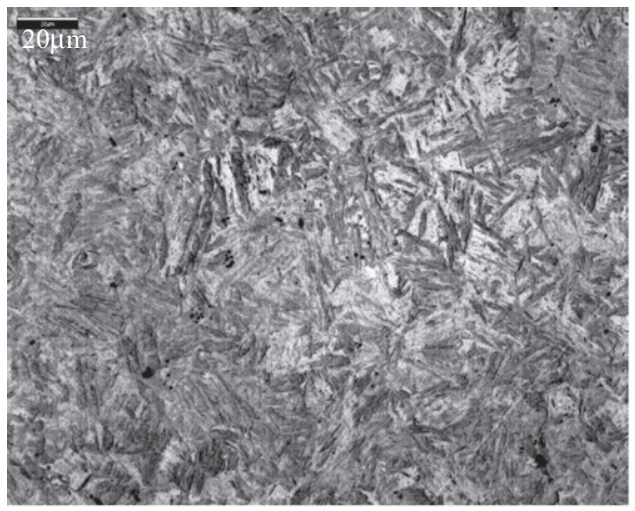

b

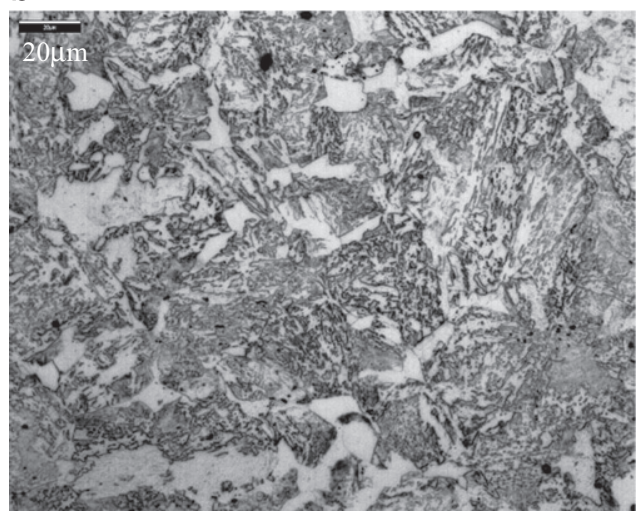

Fig. 2. Microstructure of material. (a) Series M (b) Series P.

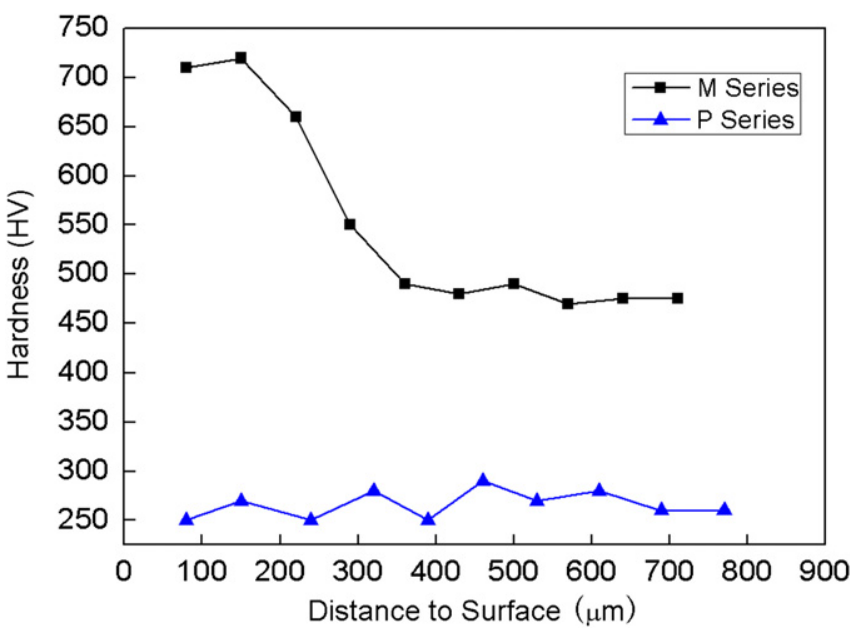

Fig. 3. Hardness distributions in section for the two series specimens.

\section{Gigacycle fatigue tests}

\section{1. $S-N$ curves}

All the tests are performed at room temperature $\left(20^{\circ} \mathrm{C}\right)$, with stress ratio $\mathrm{R}$ being 0.1 , using compressed air to cool the specimens in ultrasonic fatigue test with $20 \mathrm{kHz}$. The hourglass-shape axi-symmetric specimens (Fig. 4) were applied according to the reference [10]. The thickness of carburized layer for series $M$ specimens is about $300 \mu \mathrm{m}$ deep which also can be observed from

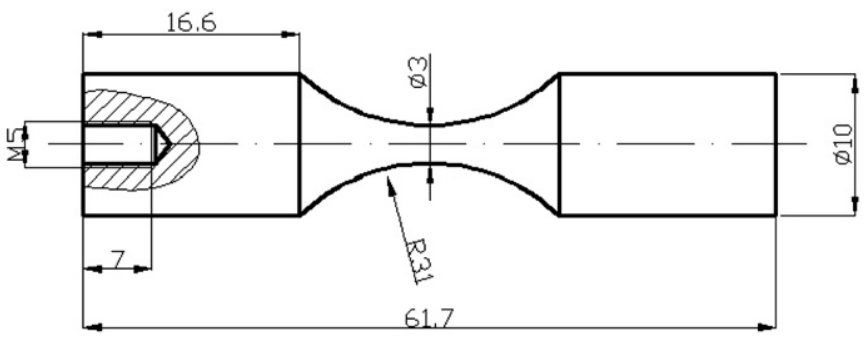

Fig. 4. Dimensions of specimen.

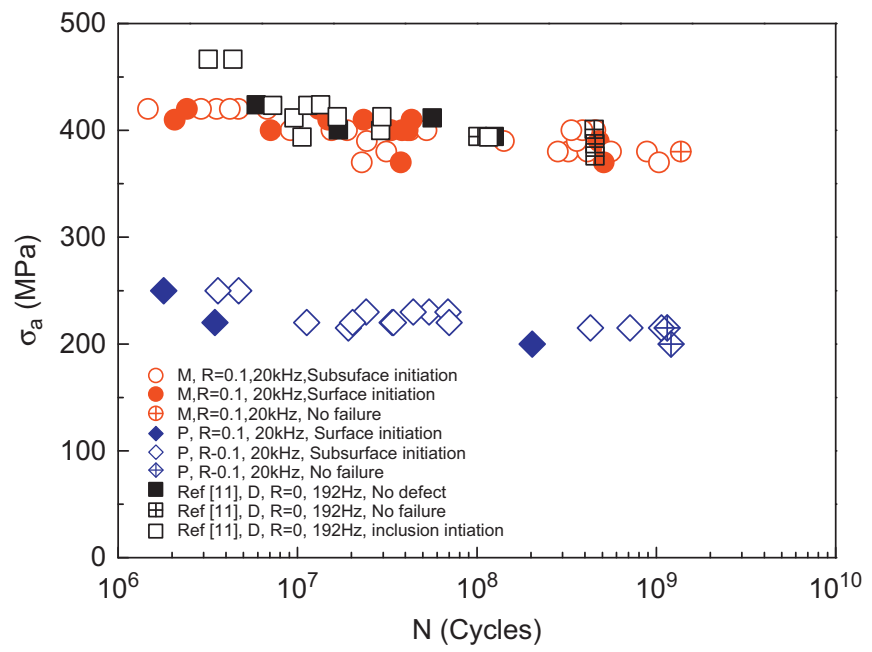

Fig. 5. VHCF test results for Series $\mathrm{M}, \mathrm{P}(R=0.1)$ and compared with Ref. [11] (series $\mathrm{D}, R=0$ ).

the hardness measurement of Fig. 3. The S-N curves in the VHCF regime are given in Fig. 5 for each series. By comparing VHCF test results of series $M$ with series $P$, big difference of the fatigue strength appears between $10^{6}$ and $10^{9}$ cycles. The fatigue strength of series P at $10^{9}$ cycles is around $200 \mathrm{MPa}$ (Fig. 5), far lower than that of series M. The fatigue test results of reference [11] (Variant D) are also plotted in the Fig. 5 (square points) with $R=0$, test frequency $192 \mathrm{~Hz}$ to comparing with the ultrasonic fatigue test results for SAE 5120.

\subsection{Thermal dissipation tests}

In order to obtain the temperature evolution on the specimen's surface, an infrared camera is employed, whose spectral range is near the infrared domain (the wavelengths between $3.7 \mu \mathrm{m}$ and $4.8 \mu \mathrm{m})$. The camera was calibrated by a black body in a temperature range $20-400{ }^{\circ} \mathrm{C}$. The specimens have been painted with a fine coating of strongly emissive black and high temperature resistant layer in order to limit the errors (in this case, the emissivity coefficient is regarded as 1 ).

Three specimens M1, M2, M3 are selected from the M series to perform the thermal dissipation experiments of VHCF with compressed air cooling. The stress amplitude is $400 \mathrm{MPa}$ with $R=0.1$ (stress ratio) and the frequency is $20 \mathrm{kHz}$.

In Fig. 6, the temperature evolution at the center of the specimen is plotted as a function of number of cycles for the steel. For the same material, in the same test condition, the amplitude of temperature increasing depends on the stress amplitude and stress ratio under a given number of cycles [7]. The initial increase of temperature during the test is followed by a relative stabilization corresponding to a balance between the dissipated mechanical energy and the lost thermo energy by convection and radiation at the specimen surface and by conduction 
inside the specimen. Before the failure of the specimen, temperature has a significant increase in a short time due to crack propagation from a defect.

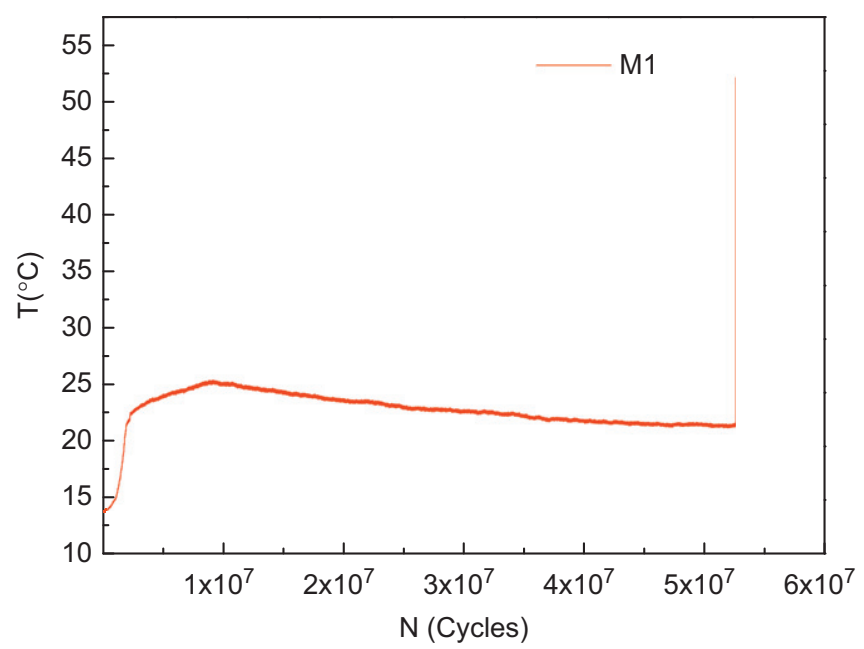

Fig. 6. Temperature evolution with cycles (specimen M1).
Infrared imaging technique can reveal the temperature distribution at certain cycles before the failure of the specimen (Fig. 7a). The temperature curve near the end of the test for specimen M1 is enlarged and shown in Fig. 7b where the corresponding images of the points are numbered and displayed. As reported in reference [6,7], the temperature rises rapidly before the failure of the specimen.

\section{Fracture surface observations}

The fracture surfaces of the specimens for thermal dissipation tests (M1, M2, M3) were analyzed by optical microscope and scanning electron microscope (SEM). Owing to the surface carburization, it has a different zone at the circumference of the section as shown in Fig. 8a.

For this low alloyed chromium steel, the crack initiation site is mainly beneath the surface. A "fish eye" may be located on the inclusions (non-metallic inclusions) as shown in Fig. 8b and Fig. 8c. The inclusion crack initiation site looks like a dark point named as "Optical Darkness Area" (ODA) by Murakami [3], or "Fine Granular Area" (FGA) by Sakai [12] or "Granular Bright Facet" (GBF) by Shiozawa [13]. The formation of ODA (also called

a

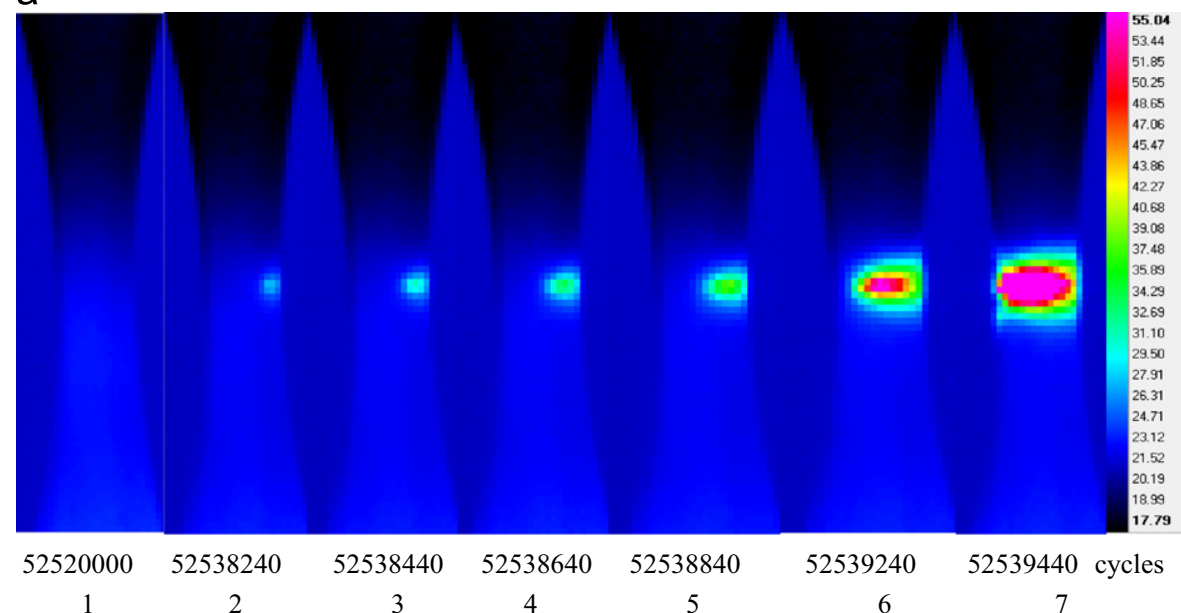

b

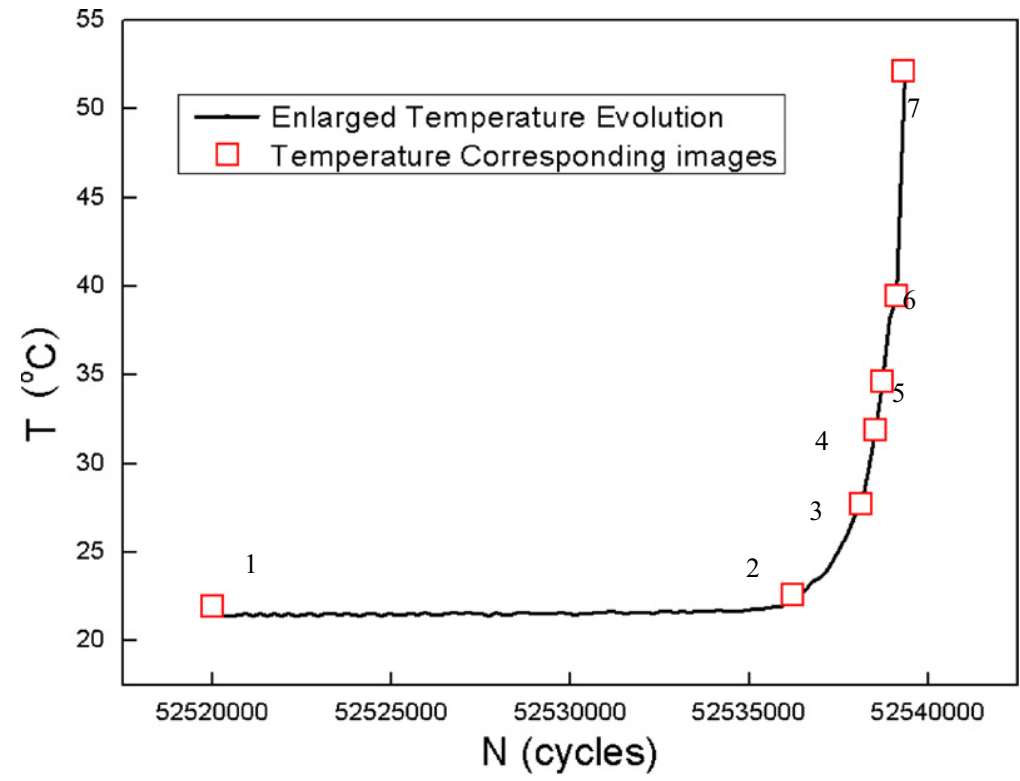

Fig. 7. Temperature evolution on the M1 specimen surface during ultrasonic fatigue test. (a)Temperature field changing with crack propagation in surface of specimen M1. (b) Enlargement of the test end. 
a

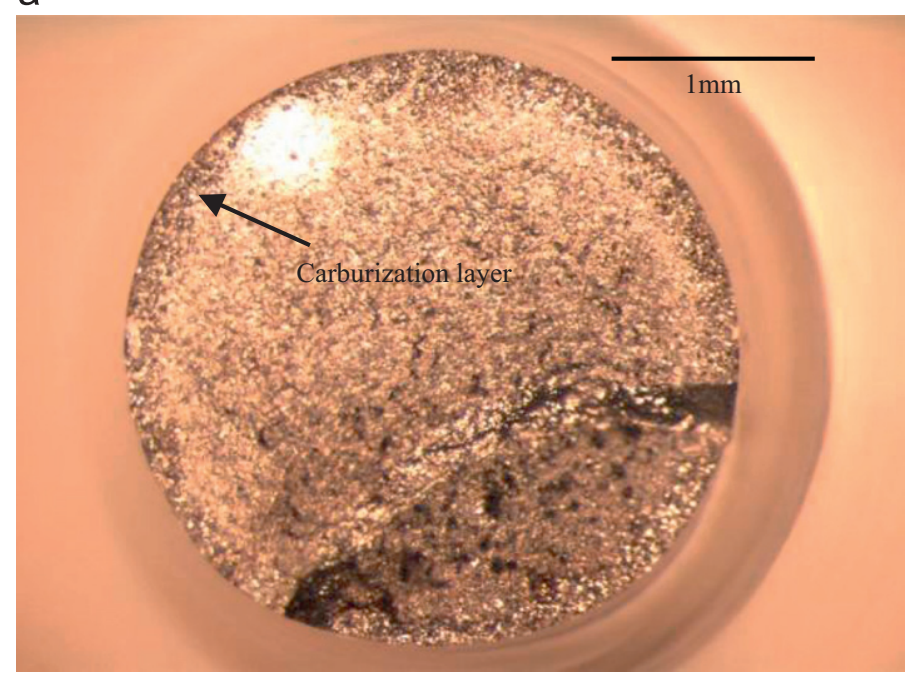

b

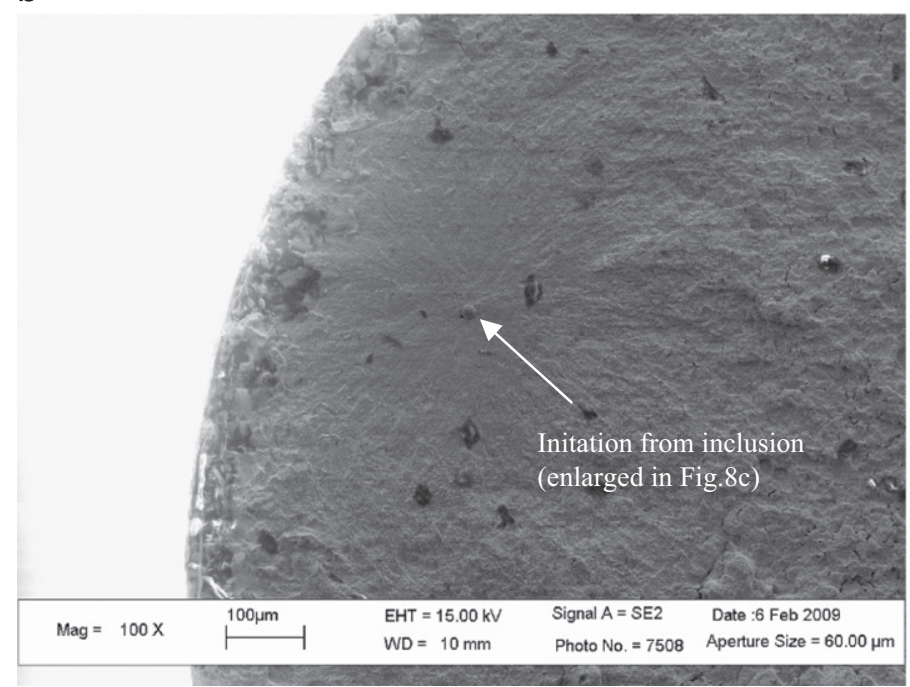

C

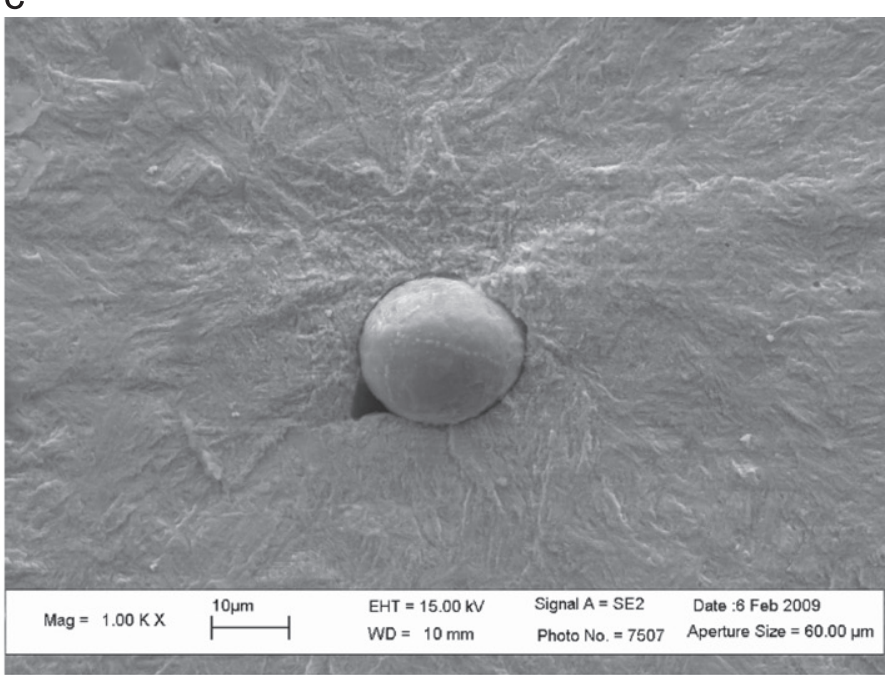

d

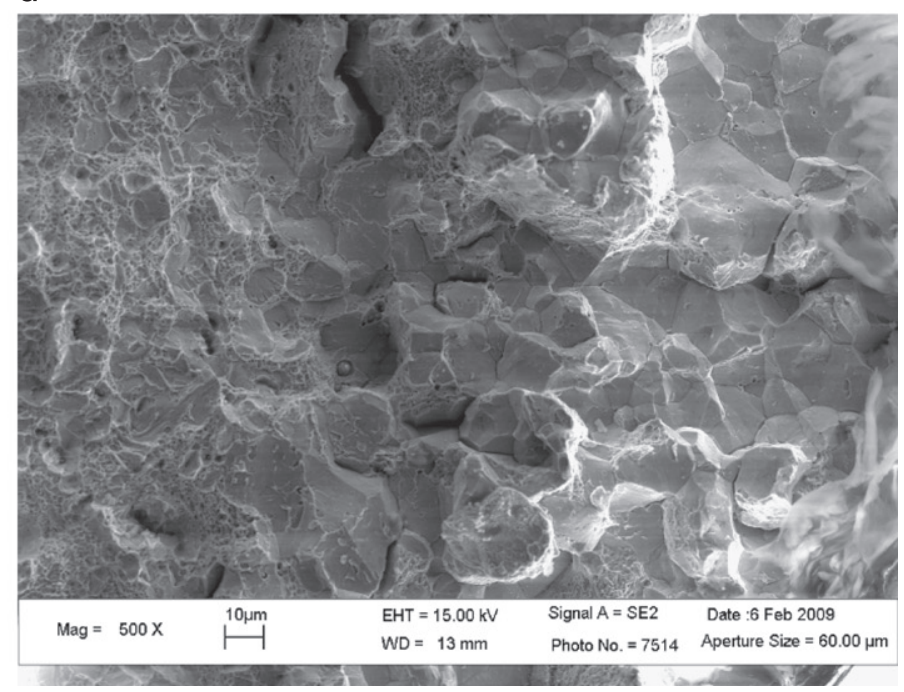

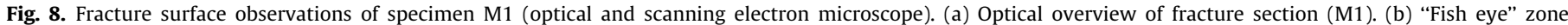
(M1, SEM). (c) Inclusion in the center of the "fish eye" (M1, SEM). (d) Intergranular fracture in carburized layer (M1, SEM).

FGA/GBF) seems to be caused by the local micro structurally irreversible portion of cumulative cyclic plastic strain. If the initiation is in subsurface, the final fracture in the carburized layer is intergranular (Fig. 8d). This zone is brittle and the final fracture happens there.

\section{Crack growth analysis}

\subsection{Determination of crack propagation cycles at the second stage}

As analyzed in previous section and reference [4], the crack starts from a defect with a size $a_{\text {int }}$ (initiation size, Fig. 9) after initiation cycles damaged $\left(N_{i}\right)$. As "ODA" with size $a_{0}$ (Fig. 9) are formed around inclusions, and related to the crack propagation with very low speed [8], it can be regarded as the crack propagation stage I. The following crack growth period until failure is considered as the stage II. All the stages are governed by the Paris law [5]. A large number of cycles $\left(N_{P I}\right)$ are used to form the zone of "ODA" [8]. The self heating effect caused by the very slow crack propagation speed in zone "ODA" seems difficult to be distinguished from the background of fatigue dissipation by the

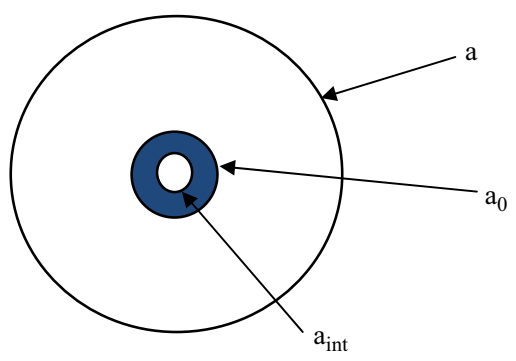

Fig. 9. Schematic figure for "fish eye" (a: size of "fish eye"; $a_{0}$ : size of "ODA"; and $a_{\text {int }}:$ size of inclusion).

infrared observation method in specimen's surface. But, when the length of crack exceeds $a_{0}$, beyond the zone "ODA", the crack growth entering the stage II, the process is accelerated [5]. Large heating generated owning to the fatigue plastic deformation at the tip of the crack is rapidly accumulated and conducted to the nearest surface of the specimen, where the temperature is raised prominently. The number of cycles at crack growth stage II $\left(N_{p I I}\right)$ seems to be capable to be measured by the infrared camera (Fig. 10). 


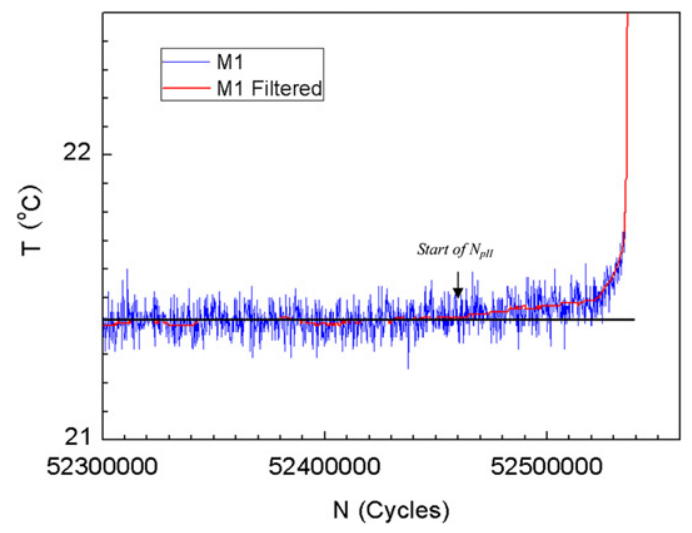

Fig. 10. Determination of crack initiation cycles $N_{i}$ by temperature evolution (specimen M1; start of $N_{p I I}=52,460,000$ cycles).

The evolution of the maximum temperature point recorded by the infrared camera, at the surface of the specimen M1 in the period of fatigue crack growth is shown in Fig. 10. In order to determine the number of cycles at crack propagation period, the noise of temperature evolution is reduced by filtering treatment for specimen M1.

By identifying the beginning of the temperature increase in the filtered temperature curves before the failure of specimen, the number of cycles $N_{\text {pII }}$ after the "ODA" forming can be determined. When the temperature increases more than the average level before the sharply rising, the initiation point could be found (Fig. 10). The crack propagation cycles at stage II $\left(N_{p I I}\right)$ could be estimated by Eq. (1).

$N_{p I I}=N_{a_{0}-a}=N_{f}-N_{i}-N_{p I}$

With $N_{f}$ : number of cycles at failure; $N_{i}$ : number of cycles for crack initiation; $N_{p I}$ : number of cycles of crack growth at stage I; $N_{\text {pII }}$ : number of cycles of crack growth at stage II. At the cycle $_{i}+N_{p I}$, it is regarded as the start of crack growth in stage II which has a prominent heating dissipation and can be detected by infrared camera (Fig. 10).

\subsection{Paris-Bathias model}

The crack propagation law in the "fish eye" has been modeled by the Paris-Hertzberg [14]

$\frac{d a}{d N}=\mathrm{b}\left(\frac{\Delta K}{\Delta K_{0}}\right)^{3}$

Where $a$ is the crack length; $\mathrm{N}$ is the number of cycles from the beginning of the test; $\Delta K$ is the stress intensity factor; $\mathrm{b}$ is Burgers vector modulus; $\Delta K_{0}$ is the stress intensity factor corresponding to the crack length $a_{0}$ (crack length at the threshold corner), which corresponds the "ODA" size of crack at the stage II.

The stress intensity factor of crack tip is proportional to the root square of crack radius

$\Delta K=\frac{2}{\pi} \Delta \sigma \sqrt{\pi a}$

Therefore

$\frac{d a}{d N}=\mathrm{b}\left(\frac{a}{a_{0}}\right)^{3 / 2}$

Notice that at the crack propagation threshold

$\frac{\Delta K_{0}}{E \sqrt{\mathrm{b}}}=1$
The Paris-Bathias (P-B) model for estimating the number of crack in "fish eye" is written as follows by replacing $a_{0}$ in the Eq. (6) with $\pi E^{2} b / 4 \Delta \sigma^{2}$ from the Eq. (5).

$N_{p I I} \approx \frac{2 a_{0}}{b}=\frac{\pi E^{2}}{2(\Delta \sigma)^{2}}$

$N_{p I I}$, the number of cycles of crack propagation at stage II, which only depends on the stress range $(\Delta \sigma)$ imposed to the specimen and elastic modulus (E). Eq. (6) is simplified after integration from Eq. (4), due to the term $\left(1 /(a)^{1 / 2}\right)$ being a small one comparing with $\left(1 /\left(a_{0}\right)^{1 / 2}\right)$ and being neglected in the model. If the loads and the materials of the specimens are the same, the prediction of crack propagation cycles could be the same. For M1, M2 and M3, the stress amplitude is the $400 \mathrm{MPa}$ and the elastic modulus is $209 \mathrm{GPa}$, so the predicted crack propagation is 108,180 cycles at stage II.

But the size of the crack initiation and "ODA", the initiation position and the carburization surface treatment also influence the crack growth, which should be considered into the model. Thanks the thermal dissipation test, it permits to determine the number of cycles of the crack propagation at stage II. The improved model is compared with the thermal dissipation test results in the next section of the article.

\subsection{Crack growth cycles correction}

According to the crack propagation path analysis in Section 4, Fig. 10 schematically shows the crack initiation size (inclusion) $a_{\text {int }}$, the eccentricity of the crack center e (considering axial symmetry of specimen), as well as the thickness of carburization layer L. Eq. (6) is integrated with integral upper and lower limits. Lower limit (crack length at the threshold corner: $a_{0}$ ) is determined by "fish eye" fractographic analysis from $a_{\text {int }}$ (size of inclusion) with assumption $a_{0}=\left(a_{\text {int }} / 0.94\right)$ [6]. Upper limit is set as $R_{1}(1-e)-L$ by taking into account the eccentricity of circular crack center $\mathrm{e}$ and the crack length $\mathrm{L}$ inside the carburization layer which is brittle (Fig. 10).

$N_{p I I}=\frac{2 a_{0}}{\mathrm{~b}}\left(1-\sqrt{\frac{a_{0}}{R_{1}(1-e)-L}}\right)$

Referring the Eq. (6), $N_{\text {pII }}$ can be rewritten as

$N_{p I I}=f_{p} \frac{\pi E^{2}}{2(\Delta \sigma)^{2}}$

$f_{\text {pII }}=\left(1-\sqrt{\frac{a_{0}}{R_{1}(1-e)-L}}\right)$, a correction factor, is used to correct the crack propagation cycles at the second stage and depends on the size of crack $a_{0}$, the position of initiation $e$ and the brittle length $L$ caused by carburization effect.

The Table 2 shows the crack information for the three specimens (M1, M2, M3) and the number of cycles of crack propagation by detection of infrared camera. The prediction of Paris-Bathias model is $N_{\text {pII }}=1.08 \times 10^{5}$ cycles by applying the Eq. (6) which overestimates the number of cycles due to simplification of the integration of the Eq. (4). According to the parameters of crack obtained by the observation of ${ }^{\prime}$ optical microscope and scanning

Table 2

Parameters, prediction and estimation compared with infrared camera tests.

\begin{tabular}{llllllll}
\hline NO. $\begin{array}{l}a_{\text {int }} \\
(\mu \mathrm{m})\end{array}$ & $e$ & $\begin{array}{l}L \\
(\mu \mathrm{m})\end{array}$ & $N_{f}$ & $\begin{array}{l}N_{i}+N_{p I} \\
(\text { Exp. IR) }\end{array}$ & $\begin{array}{l}N_{p I I} \\
(\text { Exp. IR) }\end{array}$ & $\begin{array}{l}N_{p I I} \\
\text { (present model) }\end{array}$ \\
\hline M1 & 10.7 & 0.79 & 140 & $52,540,000$ & $52,460,000$ & 80,000 & 80,592 \\
M2 & 13.5 & 0.80 & 120 & $23,400,000$ & $23,330,000$ & 70,000 & 77,625 \\
M3 & 14.7 & 0.84 & 140 & $42,500,000$ & $42,440,000$ & 60,000 & 65,402 \\
\hline
\end{tabular}


electron microscope (SEM), the calculation of the Eq. (8) and the number of cycles of crack growth determined by infrared camera are listed in Table 2 for comparison. The results of the model with correction factor are closer to those of the infrared tests.

\subsection{Thermo mechanical crack growth model}

The crack initiation is accompanied by plastic deformation around the flaw in subsurface. The generated and dissipated heat always concentrates on the flaw where the plastic deformation is important after crack initiation.

In crack propagation stage II, the local temperature increment is closely related to the fatigue crack growth before the failure of specimen [6,7]. The plastic deformation of the crack tip movement time-related heat reaches to the specimen surface and causes the temperature to rise. When the crack reaches the carburized layer, a brittle failure happens there (Fig. 8d). In terms of the Eq. (7), considering the crack propagation factor, the crack growth equation in reference [6] can be adapted as follows:

$a=f_{p I I} \frac{\pi E^{2} b}{4 \Delta \sigma^{2}} \frac{1}{\left(1-\left(N_{p I I} / N_{C}\right)\right)^{2}}$

Where, $N_{C}=\left(\pi E^{2} / 2 \Delta \sigma^{2}\right)$ is the Paris-Bathias' prediction. The crack propagation cycles $\left(N_{p I I}\right)$ at stage II will converge to $N_{p I I}$ when the crack $a$ growths to an unlimited length. It is obvious that: $N_{p I I}<N_{C}$ in Eq. (9).

When the plastic deformation zone of the crack tip is surrounded by elastic stress field, in the plastic deformation zone, strain can be assumed as a uniform distribution. Thermal dissipated power of unit of crack length growth per cycle is proportional to the square of the radius of cyclic crack tip plastic zone [15] and can be described as

$P \propto r_{R}^{2}$

After the crack is initiated, the size of plastic deformation zone ahead of the fatigue crack is proportional to the square of the stress intensity factor. The monotonic plastic deformation zone radius in plane strain condition is: $r_{y}=\left(K^{2} / 6 \pi \sigma_{y}^{2}\right)$. But in the case of cyclic plastic deformation, the radius of the zone is derived by replacing $K$ by $\Delta K$ and $\sigma_{y}$ by $2 \sigma_{y}^{\prime}$. If the cyclic fatigue crack in subsurface is considered in plane strain state, the radius of the zone is rewritten as follows:

$r_{R}=\frac{\Delta K^{2}}{24 \pi \sigma_{y}^{\prime 2}}$

where, $\sigma_{y}^{\prime}$ is the cyclic yield stress; $\Delta K$ is the stress intensity factor which ranges between $\sigma_{\min }$ and $\sigma_{\max }$ in fatigue test.

If Eqs. $(9,11)$ are introduced into (10), the dissipation power at crack tip per cycle is

$P\left(N_{p I I}\right)=\frac{P_{0}}{\left(1-\left(N_{p I I} / N_{C}\right)\right)^{4}}$

where, $P_{0}=\eta\left(E^{4} b^{2} f_{p}^{2} \Delta \sigma^{2} / 576 \pi^{2} \sigma_{y}^{\prime} 4\right)$ is the dissipation power at the beginning of crack propagation $\left(a=a_{0}\right) ; \eta$ : coefficient of crack propagation dissipation related to the material. For the model, the parameter identification is only for $\eta$ in Eq. (12) through the temperature evolution in the period of crack propagation of the test. Series $M$ has the same material in the bulk, so, the value of the coefficient of the crack propagation dissipation $(\eta)$ should be constant for the same material.

The specimen is axis-symmetric, and the circular crack is in the symmetrical plane of the specimen. Because the center of a circular crack is eccentric in the cross-section of specimen, $1 / 2$ specimen is taken into account to create a finite element model. The schematic figure (Fig. 11) displays the heat source in the

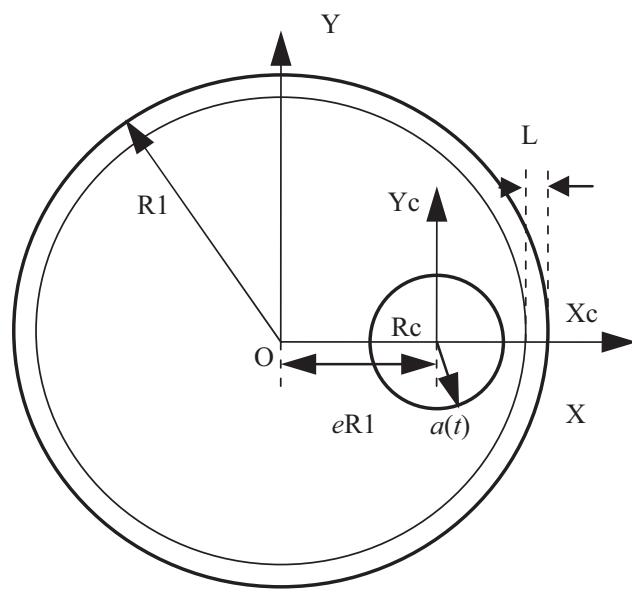

Fig. 11. Schematic figure of circular crack in fracture section.

fracture section. The heat source related to fatigue crack lies in the crack tip plastic deformation zone, which reveals a ring shape area growing with cycles increasing and its center remains unchanged. In order to compare with thermal dissipation test results of VHCF in crack growth stage, numerical thermal conduction calculation was performed to determine the temperature distribution in the surface of specimen by heat conduction.

The movement of heat source can be given out in the function of the number of crack propagation cycles [6]

$\rho C \frac{\partial T}{\partial N}=\frac{P(N)}{2} \delta\left(r_{c}-a(N)\right) \delta(z)+\lambda \nabla^{2} T$

The polar radius of coordinate of local system $\left(\mathrm{O}_{c}, \mathrm{X}_{c}, \mathrm{Y}_{\mathrm{c}}\right)$ corresponds to the radius of circular crack in Fig. 11. $\delta$ is the Dirac function; $\nabla^{2}$ is Laplace operator. Parameter $\rho\left(7850 \mathrm{~kg} / \mathrm{m}^{3}\right)$, $C\left(460 \mathrm{~J} \mathrm{~K}^{-1} / \mathrm{kg}\right), \lambda\left(52 \mathrm{~W} \mathrm{~K}^{-1} / \mathrm{m}\right)$ are the material density, specific heat capacity and thermal conductivity respectively. Because the crack propagation time is short, the convection is ignored and it is assumed that the specimen surfaces are in adiabatic state. Taking into account the symmetry of the specimen, crack propagation surface is considered adiabatic too. Boundary conditions for FEM model are: $\lambda\left(\partial T / \partial r_{\left(r=R_{1}\right)}\right)=0, \lambda\left(\partial T / \partial z_{(z=0)}\right)=0, \lambda\left(\partial T / \partial z_{(z=l)}\right)=0$. Initial temperature of specimen before crack growth is $T_{(t=0)}=T_{0}$.

\subsection{Simulation results and discussion}

The number of cycles of crack propagation at stage II can be determined and listed in Table 2, through the curve of temperature increment $(\Delta T)$ versus cycles. The parameter $\eta$ is identified as $3.54 \times 10^{-7} \mathrm{~J} / \mu \mathrm{m}^{3}$ (for series $\mathrm{M}, \sigma_{y}^{\prime}=750 \mathrm{MPa}$ ), by the test temperature evolution $(\Delta T)$ of the M2 specimen and applied to the thermal simulation and predictions for the tests of M1 and M3.

The temperature distribution of the M2 specimen in fracture surface at different crack propagation cycles are obtained by the FEM model calculation in Fig. 11 . When $N_{p I I}=20,000$ cycles after the crack initiation (Fig. 12a), due to the small size of the crack, the main temperature field distributes around the short crack As the crack size increasing, its tip approaches to the surface of the specimen and the plastic zone releases more heat, leading to the temperature rise. It is very significant at $N_{p I I}=64,000$ cycles (Fig. 12b). In Fig. 13, the FEM simulations of the evolution of temperature increase at the highest temperature point of the surface of specimen during the VHCF crack growth coupled with thermal dissipation model is in agreement with the experimental temperature increment curves. The temperature evolution curves of the dissipation tests indicate that the number of cycles for 


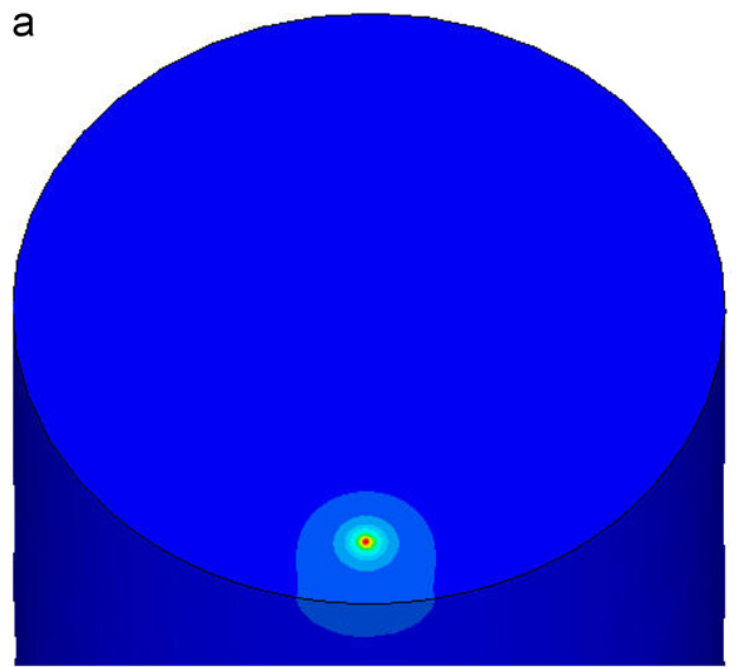

$.128 \mathrm{E}-03$
.001492
.002855
.004219
.005582
.006945
.008309
.009672
.011036
.012399

b

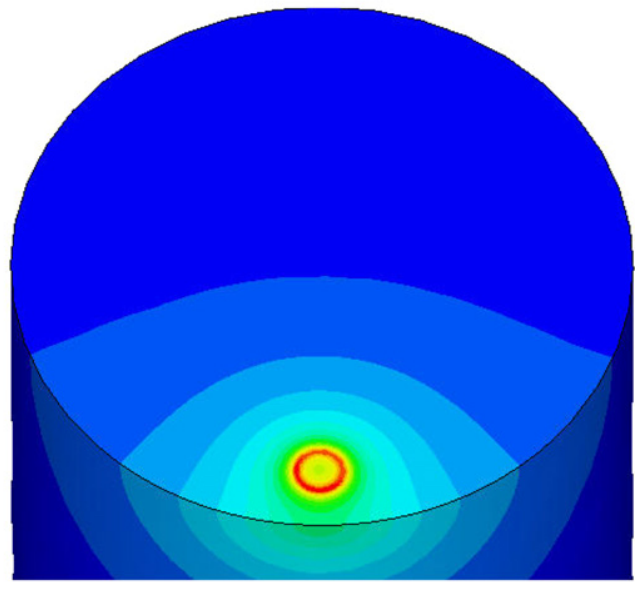

Fig. 12. Numerical simulation of temperature distribution for different cycles after crack initiation (M2) (b) $\mathrm{N}_{p I I}=20000$ cycles and (b) $\mathrm{N}_{p l l}=64000$ cycles.

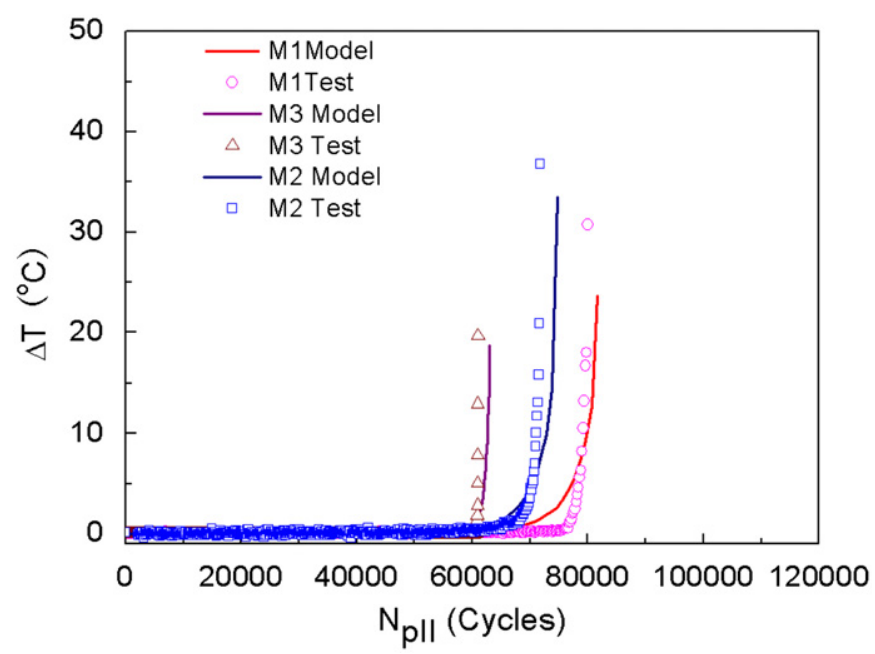

Fig. 13. Temperature evolutions in test and simulations with crack propagation cycles.

crack propagation at stage II (from "ODA" to "fish eye") is far lower than that for fatigue life, which implies that the crack propagation at stage II is very fast under ultrasonic fatigue load.

\section{Conclusions}

In this paper, the VHCF strength and thermal dissipation tests of steel SAE 5120 are investigated. Considering the effect of surface carburization treatment, an improved VHCF crack propagation model coupled with thermal dissipation is proposed. The main conclusions of the article are:

1. The VHCF strength at $10^{9}$ cycles only reaches $210 \mathrm{MPa}(R=0.1)$ for the SAE 5120 steel in the normalized condition. After carburizing and quenching treatment, the material fatigue strength is improved significantly. Its VHCF strength at $10^{9}$ cycles $(R=0.1)$ is about $350 \mathrm{MPa}$.

2. Comparing with the failure cycles, the number of cycles for crack propagation from "ODA" to "fish eye" (stage II) is very small. Most of the fatigue life is consumed at the crack initiation and "ODA" forming stage even after surface carburization. An improved model from Paris-Bathias taking into account the final brittle fracture is developed. Due to the brittle layer at the specimen periphery, the number of cycles for crack propagation at stage II is reduced.

3. The estimation of the number of cycles after crack initiation with the correction factor is verified by the thermal dissipation tests. FEM simulation of heating dissipation for the crack propagation results explains the temperature evolution with the propagation cycles inside a "fish eye". For the same chosen point of specimen surface, the history of temperature increase $(\Delta T)$ is in coincidence with thermal dissipation test. The calculated number of cycles for the second stage of crack propagation (by the improved Paris model) is in good agreement with the fatigue dissipation test.

\section{Acknowledgment}

The authors thank for National Natural Science Research Foundation of China to provide financial supporting (No. 51101107).

\section{References}

[1] C. Bathias, L. Drouillac, P. Le François, Int. J. Fatigue 23 (2001) 143-151.

[2] I. Marines, G. Dominguez, G. Baudry, J.-F. Vittori, S. Rathery, J.-P. Doucet, C. Bathias, Int. J. Fatigue 25 (2003) 1037-1046.

[3] Y. Murakami, Metal Fatigue: Effects of Small Defects and Nonmetallic Inclusions, Elsevier, Oxford, 2002, pp. 280-285.

[4] Zhiyong Huang, Danièle Wagner, Claude Bathias, Paul C. Paris, Acta Mater. 58 (2010) 6046-6054.

[5] Paul C. Paris, Israel Marines Grarcia, Richard W. Hertzberg, J. Keith Donald, in: Proceedings of the Third International Conference on Very High Cycle Fatigue (VHCF-3), Risumeiken University, Kusatsu, Japan, 2004, pp. 16-19.

[6] N. Ranc, D. Wagner, P.C. Paris, Acta Mater. 56 (2008) 4012-4021.

[7] D. Wagner, N. Ranc, C. Bathias, P.C. Paris, Fatigue Fract. Eng. Mater. Struct. 33 (2009) 12-21.

[8] M. Nakajima, N. Kamiya, H. Itoga, K. Tokaji, H.N. Ko, Int. J. Fatigue 28 (2006) 1540-1546.

[9] Z.Y. Huang, W. Du, C. Bathias, D. Wagner, Mater. Sci. Forum 636-37 (2) (2010) 1459-1466.

[10] C. Bathias, P.C. Paris, Gigacycle Fatigue in Mechanical Practice, Marcel Dekker, New York, 2005, pp. 54-70.

[11] K. Burkart, H. Bomas, H.-W. Zoch, Int. J. Fatigue 33 (2011) 59-68.

[12] T. Sakai, in: J.E. Allison, J.W. Jones, J.M. Larsen, R.O. Ritchie (Eds.), Proceedings Very High Cycle Fatigue 4, The Minerals, Metals and Materials Society, Warrendale, PA, 2007, pp. 3-12.

[13] K. Shiozawa, Y. Morii, S. Nishino, L. Lu, Int. J. Fatigue 28 (2006) 1520-1532.

[14] Israel Marines-Garica, Paul C. Paris, Hiroshi Tada, Claude Bathias, Mater. Sci. Eng. A 468-470 (2007) 120-128.

[15] Claude Bathias, Jean Paul Bailon, La fatigue des matériaux et des structures, Paris, Editions. 